\title{
ALK, NUT, and TRK Do Not Play Relevant Roles in Gastric Cancer-Results of an Immunohistochemical Study in a Large Series
}

\author{
Marie-Isabelle Glückstein ${ }^{1}$, Sebastian Dintner ${ }^{1}$, Silvia Miller ${ }^{1}$, Dmytro Vlasenko ${ }^{2}$, Gerhard Schenkirsch ${ }^{3}$, \\ Abbas Agaimy ${ }^{4}$ (D), Bruno Märk1 ${ }^{1, *(D)}$ and Bianca Grosser ${ }^{1}$ \\ 1 General Pathology and Molecular Diagnostics, Medical Faculty, University of Augsburg, \\ 86159 Augsburg, Germany; Marie-Isabelle.Glueckstein@uk-augsburg.de (M.-I.G.); \\ Sebastian.dintner@uk-augsburg.de (S.D.); Silvia.Miller@uk-augsburg.de (S.M.); \\ Bianca.Grosser@uk-augsburg.de (B.G.) \\ 2 General, Visceral, and Transplantation Surgery, Medical Faculty, University of Augsburg, \\ 86159 Augsburg, Germany; Dmytro.Vlasenko@uk-augsburg.de \\ 3 Tumor Data Management, Medical Faculty, University of Augsburg, 86159 Augsburg, Germany; \\ Gerhard.Schenkirsch@uk-augsburg.de \\ 4 Institute of Pathology, Friedrich-Alexander-University Erlangen-Nürnberg, University Hospital Erlangen, \\ 91054 Erlangen, Germany; Abbas.Agaimy@uk-erlangen.de \\ * Correspondence: Bruno.Maerk1@uka-science.de
}

check for

updates

Citation: Glückstein, M.-I.; Dintner

S.; Miller, S.; Vlasenko, D.;

Schenkirsch, G.; Agaimy, A.; Märkl, B.; Grosser, B. ALK, NUT, and TRK

Do Not Play Relevant Roles in

Gastric Cancer-Results of an

Immunohistochemical Study in a

Large Series. Diagnostics 2022, 12, 429.

https://doi.org/10.3390/

diagnostics12020429

Academic Editor: Takuji Tanaka

Received: 11 January 2022

Accepted: 4 February 2022

Published: 7 February 2022

Publisher's Note: MDPI stays neutral with regard to jurisdictional claims in published maps and institutional affiliations.

Copyright: (C) 2022 by the authors. Licensee MDPI, Basel, Switzerland. This article is an open access article distributed under the terms and conditions of the Creative Commons Attribution (CC BY) license (https:// creativecommons.org/licenses/by/ $4.0 /)$.

\begin{abstract}
ALK, NUT, and TRK are rare molecular aberrations that are pathognomonic for specific rare tumors. In low frequencies, however, they are found in a wide range of other tumor entities. This study aimed to investigate the frequency, association with clinicopathological characteristics, and prognosis of the immunohistochemical expressions of ALK, NUT, and TRK in 477 adenocarcinomas of the stomach and gastroesophageal junction. Seven cases (1.5\%) showed an expression of TRK. In NGS, no NTRK fusion was confirmed. No case with ALK or NUT expression was detected. ALK, NUT, and NTRK expression does not seem to play an important role in gastric carcinomas.
\end{abstract}

Keywords: gastric cancer; TRK; ALK; NUT; immunohistochemistry

\section{Introduction}

Gastric cancer is ranked as the sixth most common cancer entity worldwide, having accounted for approximately 780,000 cancer-associated deaths in 2018 [1]. To date, only a few prognostic and therapeutic biomarkers have been identified for gastric cancer. To date, the most important therapeutic marker in gastric carcinoma is HER2 overexpression [2]. In addition, MSI status and high PDL1 expression are independent positive prognostic factors in gastric carcinoma [3-5], while aberrant E-cadherin expression is considered an unfavorable prognostic factor and even a negative predictive factor for chemotherapy response [6]. Additionally, two generally accepted molecular classifications for gastric carcinomas have been proposed that have both prognostic and therapeutic implications, namely the Cancer Genome Atlas (TCGA) and Asian Cancer Research Group (ACRG) classification $[7,8]$. Furthermore, MET amplification and overexpression are thought to play a crucial role in gastric carcinogenesis, but this remains to be found as a predictive factor for the response to anti-MET antibodies [5].

In addition to common drivers, such as $R A S$ and $R A F$ genes, there exists a group of rare molecular alterations that are mainly associated with specific tumor types but occur at a low frequency in completely different tumor entities as drivers with high oncogenic energy. Currently, few studies evaluating these aberrations in gastric cancer with small sample sizes exist. Anaplastic lymphoma kinase $(A L K)$ fusions are known as oncogenic drivers of anaplastic large-cell lymphoma (ALCL), which is ALK positive in $50 \%$ of cases $[9,10]$. In 
non-small cell lung cancer (NSCLC), $A L K$ rearrangements are detected in approximately $5 \%$ of cases. In this relatively small proportion of NSCLCs, tyrosine kinase inhibitors represent a valid therapy option $[11,12]$. To date, ALK alteration has been detected in only a few cases of gastric carcinoma [13-15].

Neurotrophic tyrosine receptor kinases (NTRKs) consist of three protooncogenes (NTRK 1, 2 and 3) encoding the three transmembrane proteins of the tropomyosin receptor kinases receptor family (TRKs) A, B, and C. The TRKs profoundly influence the development and function of the central as well as the peripheral nervous systems. Gene fusion can give rise to a chimeric oncogene represented by the ligand-dependent constitutive, uncontrolled TRK activation and thus uncontrolled activation of underlying signaling pathways. In this way, cell proliferation, migration, synaptic formatting, survival, but also invasion and angiogenesis are promoted. Similarly to ALK alterations in ALCL, NTRK alterations are specific to infantile fibrosarcoma, congenital mesoblastic nephroma, lipofibromatosis-like and inflammatory myofibroblastic tumor-like neoplasms, and secretory carcinomas of the breast and salivary glands and are potent molecular drivers of disease in these rare tumor entities. However, NTRK fusions also occur at a low frequency in a wide variety of entities, which enables the tumor-agnostic use of NTRK inhibitors [16-18]. To date, two TRK inhibitors, namely larotrectinib and entrectinib, have been approved for the treatment of solid tumors with NTRK fusion. Others are currently being evaluated in clinical trials [17-21]. In 2020, the first case of gastric carcinoma was reported in which both an NTRK gene fusion and the transcript of the same could be detected [22].

Nuclear protein in testis (NUT) is of clinical relevance in the context of so-called NUT midline carcinomas (NC). These highly aggressive tumors often, but not exclusively, originate from or have contact with the midline structures. NUT becomes the molecular driver through gene fusion with certain partner genes [23]. To date, there is only one documented case of NC localized in the stomach, which was reported by Dickson et al. in 2018 [24].

The aim of this retrospective study was to determine whether and to what extent other molecular aberrations that have been previously associated with very specific and rather rare tumors play a role in gastric cancer in a large Western cohort. For this purpose, we evaluated the frequency of alterations in ALK, NUT, and TRK in 477 carcinomas of the stomach and gastroesophageal junction.

\section{Materials and Methods}

\subsection{Patients}

Surgical resection specimens from 511 patients with adenocarcinomas of the stomach and the gastroesophageal junction that were treated between 2005 and 2018 at the Department of Visceral Surgery of the University Hospital Augsburg were included in this study (AEGII and III according to Siewert and Stein [25]). Tumors from 34 patients were excluded from this study, because of the low tumor percentage on the TMA and the final cohort consisted of 477 tumors. Among the tumors, 347 were treated with surgery alone, and 130 patients received neoadjuvant chemotherapy. Detailed clinical characteristics are summarized in Table 1. 
Table 1. Clinicopathological characteristics.

\begin{tabular}{|c|c|c|c|}
\hline \multicolumn{2}{|l|}{ Variable } & $n=477$ & $\%$ \\
\hline \multicolumn{2}{|c|}{ Median age (range) (years) } & $70.0(30.0-95.0)$ & \\
\hline \multicolumn{2}{|c|}{ Median survival (range) (months) } & $58.0(49.9-66.1)$ & \\
\hline \multirow[t]{2}{*}{ Sex } & female & 312 & $65 \%$ \\
\hline & male & 165 & $35 \%$ \\
\hline \multirow[t]{2}{*}{ T status } & $\mathrm{pT} 1 / 2$ & 159 & $33 \%$ \\
\hline & $\mathrm{pT} 3 / 4$ & 318 & $67 \%$ \\
\hline \multirow[t]{2}{*}{ N status } & negative & 178 & $37 \%$ \\
\hline & positive & 299 & $63 \%$ \\
\hline \multirow[t]{3}{*}{ Distant Metastasis } & no & 247 & $52 \%$ \\
\hline & yes & 197 & $41 \%$ \\
\hline & NA & 33 & $7 \%$ \\
\hline \multirow[t]{3}{*}{ Grading } & low grade & 162 & $34 \%$ \\
\hline & high grade & 304 & $64 \%$ \\
\hline & NA & 11 & $2 \%$ \\
\hline \multirow[t]{2}{*}{ Lymphovascular invasion } & negative & 287 & $60 \%$ \\
\hline & positive & 190 & $40 \%$ \\
\hline \multirow[t]{2}{*}{ Vascular invasion } & negative & 401 & $84 \%$ \\
\hline & positive & 76 & $16 \%$ \\
\hline \multirow[t]{2}{*}{ Lauren } & intestinal & 266 & $56 \%$ \\
\hline & non-intestinal & 211 & $44 \%$ \\
\hline \multirow[t]{3}{*}{ Localization } & proximal (AEG II/III, Cardia) & 124 & $26 \%$ \\
\hline & $\begin{array}{l}\text { non proximal } \\
\text { (Fundus/Corpus/Antrum) }\end{array}$ & 335 & $70 \%$ \\
\hline & NA & 18 & $4 \%$ \\
\hline \multirow[t]{3}{*}{ R status } & R0 & 403 & $84 \%$ \\
\hline & R1 & 54 & $11 \%$ \\
\hline & $\mathrm{Rx}$ & 20 & $4 \%$ \\
\hline \multirow[t]{5}{*}{ TCGA } & EBV+ & 25 & $5 \%$ \\
\hline & MSI & 61 & $13 \%$ \\
\hline & GS & 110 & $23 \%$ \\
\hline & CIN & 151 & $32 \%$ \\
\hline & no classification & 130 & $27 \%$ \\
\hline \multirow[t]{2}{*}{ Death } & no & 227 & $48 \%$ \\
\hline & death & 250 & $52 \%$ \\
\hline \multirow[t]{2}{*}{ Preoperative CTx } & no & 347 & $73 \%$ \\
\hline & yes & 130 & $27 \%$ \\
\hline \multirow[t]{3}{*}{ TRG $(n=130)$} & $1 b$ & 9 & $7 \%$ \\
\hline & 2 & 36 & $28 \%$ \\
\hline & 3 & 82 & $65 \%$ \\
\hline \multirow[t]{5}{*}{ CTx regimen } & Cis $/ O x+5-F U$ or Cap & 34 & $27 \%$ \\
\hline & $\mathrm{Ox}+5-\mathrm{FU}+\mathrm{Doc}$ & 45 & $35 \%$ \\
\hline & $\mathrm{Cis}+5-\mathrm{FU}+\mathrm{Epi}$ & 41 & $32 \%$ \\
\hline & $\mathrm{Ox}+\mathrm{Epi}+\mathrm{Cap}$ & 5 & $4 \%$ \\
\hline & others & 2 & $2 \%$ \\
\hline
\end{tabular}

TCGA: The Cancer Genome Atlas; EBV+: EBV positive; MSI: microsatellite instable; GS: genomically stable; CIN chromosomally instable; Cis, cisplatin; Ox, oxaliplatin; 5-FU, 5-fluorouracil; Cap, capecitabine; Doc, docetaxel; $\mathrm{Pac}$, paclitaxel; Epi, epirubicin; Others, combination of Cis/Ox with other agents or cross over between different treatment regimens. 
Response to preoperative chemotherapy was histopathologically determined and was classified into three tumor regression grades (TRG): TRG1b, TRG2, TRG3, corresponding to $<10 \%, 10 \%-50 \%$, and $>50 \%$ residual tumor cells, respectively [26]. Patients with TRG1b were classified as responders, TRG2, and TRG3 as non-responders. Patients were treated with platinum/5-fluorouracil (5FU)-based chemotherapeutic regimes (Table 1). All surgical approaches included an abdominal D2-lymphadenectomy [27].

Follow-up data were obtained from the tumor data management of the University Hospital of Augsburg. Median follow-up was calculated by the inverse Kaplan-Meier method [28].

This study was approved by the Institutional Review Board at the Ludwig-MaximiliansUniversity of Munich (reference: 20-0922) and was performed in accordance with the declaration of Helsinki.

\subsection{Tissue Microarray Construction}

All eligible histological sections were first re-evaluated using a light microscope to verify the diagnosis. Representative slides of each tumor were digitalized using a Pannoramic SCAN II scanner (3DHISTECH, Budapest, Hungary), and five areas, consisting of normal tissue $(1 \times)$, central tumor $(2 \times)$, and a tumor invasion front $(2 \times)$ were selected. Based on the marked areas, formalin-fixed paraffin-embedded (FFPE) tumor samples were subsequently automatically assembled into a tissue microarray (TMA) using a TMA Grandmaster (3DHISTECH, Budapest, Hungary) with a core size of $1 \mathrm{~mm}$.

\subsection{Immunohistochemistry and In Situ Hybridization}

Immunohistochemical staining was performed on $2 \mu \mathrm{m}$ sections from each TMA using primary antibodies for TRK (RBT-TRK (ready-to-use (RTU)), Bio SB, Santa Barbara, CA, USA, BSB-2376), NUT (C52B1 (1:50), Cell Signaling Technology, Danvers, MA, USA, 3625), and ALK (D5F3 (RTU), Roche Diagnostics, Mannheim, Germany, 790-4794). For TRK, a Ventana BenchMark ULTRA platform with an iVIEW DAB detection system was used (Roche, Mannheim, Germany). Staining for NUT and ALK was performed on a BOND Rx platform with a BOND Polymer Refine Detection Kit (Leica Biosystems, Nussloch, Germany). Adequate controls were used for the quality control of the staining (Figures 1 and 2).
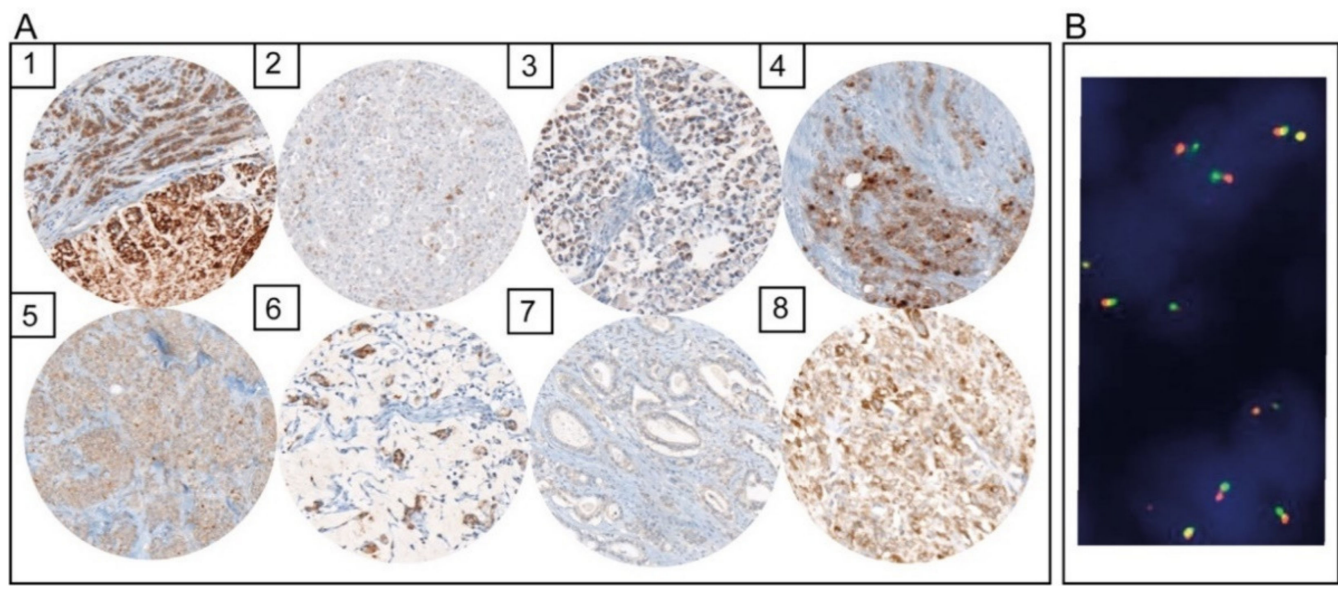

Figure 1. (A) Cases with immunohistochemical TRK expression (1-7) and a positive control of TRK immunohistochemistry (8); (B) FISH analysis of NTRK 1 of case 1 without the detection of break-apart signals. 


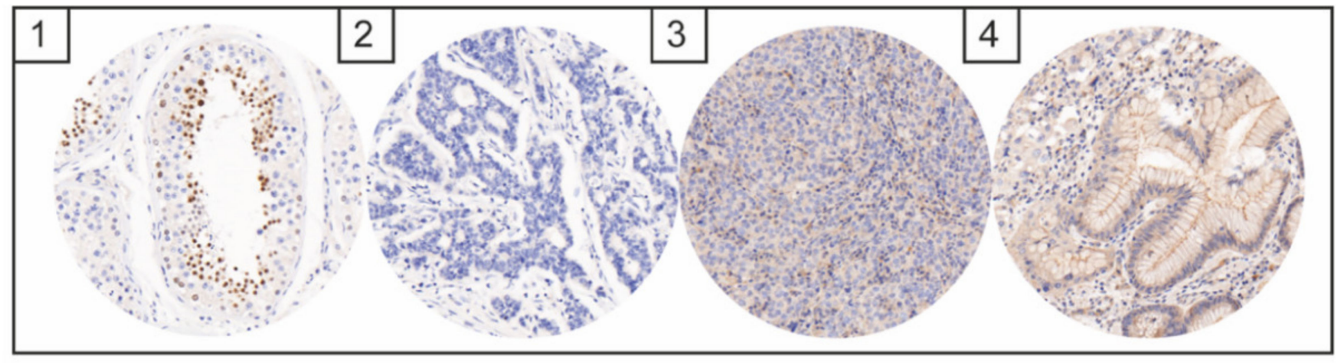

Figure 2. Images of immunohistochemical NUT expression: Spermatogenic cells as positive staining control (1); images of negative NUT staining (2-4); image with unspecific background staining in tumor cells (3); and normal foveolar epithelium (4).

The stained sections were digitalized, and evaluations were performed with a 3DHISTECH Caseviewer (3DHISTECH, Budapest, Hungary) by one pathologist (B.G.) and one trained researcher (M.G.), that independently reviewed the slides. Discrepant cases were discussed with a senior pathologist (B.M.), and a consensus was established. The investigators were blinded to both the clinicopathological data and outcome.

The immunohistochemical expression of NUT was evaluated as described by French et al. [23]. Only the staining of more than $50 \%$ of tumor cell nuclei was considered NUT positive [23]. According to Chon et al. [14], a case is considered ALK positive if at least $10 \%$ of the tumor cells showed moderate cytoplasmic, nuclear or membranous staining. The staining intensity was divided into weak (light-brown staining), moderate (mediumbrown) and strong (dark-brown) [14]. Any cytoplasmic or nuclear staining with TRK was considered positive.

\subsection{TCGA Classification}

Tumors were classified in analogy to TCGA-classification [7] as proposed by Setia et al. and Ahn et al. $[29,30]$ and, as described previously, in $\mathrm{EBV}^{+}$, mismatch repair deficient (MMRD), genomically stable (GS) and chromosomally instable (CIN) cases. Cases that showed nuclear staining by EBER-CISH were considered EBV positive. The presence of mismatch repair deficiency (MMRD) was stated in the case of loss of the nuclear expression of MSH6 or PMS2. GS cases were identified according to aberrant E-cadherin expression. E-cadherin was considered positive if membranous staining was present in more than $50 \%$ of tumor cells [31]. Tumors were classified as CIN if an aberrant p53 expression pattern was present. p53 expression was considered aberrant if tumor cells showed complete loss of nuclear expression or if they showed staining with strong intensity in more than $60 \%$. The staining of less than $60 \%$ with weak to moderate intensity was considered a wild-type expression pattern $[32,33]$. Cases that did not meet the above criteria were designated as unclassifiable.

\subsection{Next-Generation Sequencing (NGS) of NTRK-Positive Cases}

RNA isolation and quantification: A $2 \mu \mathrm{m}$-thick section was obtained from the FFPE tissue and then stained with hematoxylin and eosin (H\&E) for pathologic evaluation. Tumor cells were acquired using microdissection under histomorphological control. The percentage of tumor cells in the microdissected areas varied between $30 \%$ and $80 \%$ (mean $70 \%$ ). RNA was isolated with a Maxwell ${ }^{\circledR} 16$ LEV RNA FFPE Purification Kit (Promega, Madison, WI, USA, AS1260) and fluorometrically quantified with QuantiFluor ${ }^{\circledR}$ RNA System (Promega, Madison, WI, USA, E3310). For long-term storage, the samples were kept at $-80^{\circ} \mathrm{C}$.

Library preparation and next-generation sequencing: RNA panel sequencing was performed for the molecular analysis of gene fusions. The library was prepared using AmpliSeq ${ }^{\mathrm{TM}}$ Library PLUS for Illumina ${ }^{\circledR}$, AmpliSeq $^{\mathrm{TM}}$ for Illumina ${ }^{\circledR}$ Focus Panel RNA pool and AmpliSeq ${ }^{\mathrm{TM}}$ CD Indexes for Illumina ${ }^{\circledR}$. The RNA-input varied between 1 and $100 \mathrm{ng}$ 
RNA/sample. The final cDNA libraries were fluorometrically quantified with QuantiFluor ${ }^{\circledR}$ ONE dsDNA System (Promega, E4871), pooled to target a minimum of 100.000 reads for each tumor sample, diluted to a final concentration of $9 \mathrm{pM}$ and sequenced by synthesis on the Illumina MiSeq using paired 150 bp reads on a V2 flow cell (Illumina, San Diego, CA, USA, MS-102-2002). BCL files were converted to FASTQ and fusion files using the RNA amplicon workflow application on the LRM software from Illumina. Seven cases with immunohistochemical TRK expression were analyzed by NGS.

\subsection{Fluorescence In Situ Hybridization (FISH) Analysis of NTRK-Positive Cases}

The analyses of the seven cases with immunohistochemical TRK expression were performed on $1 \mu \mathrm{m}$-thick whole-slide tissue sections of FFPE samples. For the detection of NTRK rearrangements, ZytoLight SPEC NTRK1 (Z-2167), NTRK2 (Z-2205), or NTRK3 (Z-2206) Dual Color Break Apart Probes (Zytovision, Bremerhaven, Germany) were used according to the manufacturer's instructions.

\section{Results}

\section{NTRK, ALK, and NUT Expression}

Seven cases (1.5\%) with TRK expression were identified by immunohistochemistry (Figure 1A). Three cases (cases 1, 4, and 5) presented with moderate to strong cytoplasmic positivity in the majority of tumor cells. One case showed a moderately strong single-cell expression of TRK (case 2). One case showed very weak nuclear expression (case 7), and cases 3 and 6 presented moderately strong cytoplasmic expression in signet ring cells. In all seven cases, no fusion of the NTRK 1, 2, or 3 gene could be found by FISH (Figure 1B). In addition, next-generation sequencing revealed no NTRK fusion.

No cases with immunohistochemical NUT expression could be detected (Figure 2). Only nonspecific cytoplasmic staining reaction was seen, with no specific nuclear staining reaction. No cases with positive ALK expression could be identified (Figure 3). Weak nuclear, membranous or cytoplasmic expression was seen in six cases but in less than $10 \%$ of the tumor cells in each case.

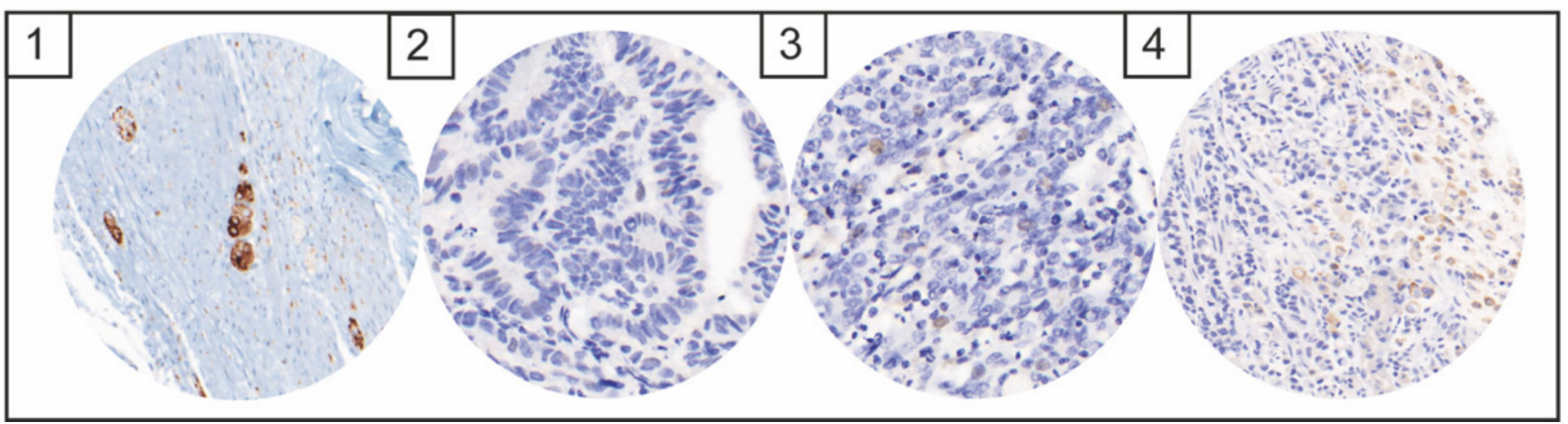

Figure 3. Images of immunohistochemical ALK expression: Ganglion cells of the appendix as a positive staining control (1), image of negative ALK staining (2), case with weak nuclear single-cell expression (3), and weak membranous unspecific staining pattern in signet ring cells (4).

\section{Discussion}

Alterations of $A L K, N T R K$, and NUT were identified in low frequencies in various tumor entities. To the best of our knowledge, no prior study has evaluated the existence of ALK, TRK, and NUT in a large cohort of gastric carcinomas [13,22,24]. This study addressed this issue and analyzed the frequencies of ALK, TRK, and NUT alterations in gastric adenocarcinomas with or without neoadjuvant CTx.

$A L K$ is a membrane-bound enzyme with tyrosine kinase activity that is physiologically present in the brain and peripheral nervous system only during the embryonic phase, which rapidly regresses after birth and is expressed in adults at low levels exclusively in the central nervous system (CNS). Detection outside the CNS is thus indicative of 
cell abnormality [34,35]. Gene fusions are strong tumor drivers and therapeutic targets amenable to tyrosine kinase inhibitors such as crizotinib [11,12,36]. Currently, the best studied $A L K$ fusions are NPM1-ALK in anaplastic large-cell lymphoma (ALCL) and EML4$A L K$ in non-small cell lung cancer (NSCLC), which harbor $A L K$ fusions in approximately $5 \%$ of cases $[9,10]$.

NUT is typically expressed exclusively in post-meiotic spermatids. Through gene fusion, NUT leads to the extensive acetylation of chromatin which alters the transcription of oncogenes, blocks the differentiation of cells, and drives uncontrolled growth [23]. NUT is responsible for the development of the highly aggressive tumor entity of NUT carcinomas (NCs) that mainly affects young adults, is associated with a very poor prognosis and has been shown not to benefit from chemotherapy [23,24,37].

In our cohort of nearly 500 gastric adenocarcinomas, no cases with ALK or NUT expression could be detected. Alese et al. [13] detected one case with ALK fusion examining 25 signet-ring-cell adenocarcinomas of the stomach by FISH. Ying et al. [15] found two $(0.44 \%)$ case of ALK-positive colorectal carcinomas but no case with an ALK-positive gastric carcinoma in 182 cases. In our study, the analysis of $A L K$ was performed only by immunohistochemistry and not using FISH. However, a recent study on lung carcinomas showed that immunohistochemistry is superior to FISH in the detection of altered ALK [36]. Dickson et al. described one case of gastric NUT-associated tumor [24]. Given the rarity of reports regarding $A L K$ and NUT alterations in gastric cancer, our results indicate that neither ALK nor NUT fusion plays a relevant role in gastric cancer.

NTRKs encode three TRKs and influence the development and function of the central and peripheral nervous systems. Gene fusion can give rise to uncontrolled TRK activation and thus the uncontrolled activation of underlying signaling pathways, such as the MAPKERK or the PI3K. To date, two TRK inhibitors, namely larotrectinib and entrectinib, have been approved for the treatment of solid tumors with NTRK fusion. Others are currently being evaluated in clinical trials [17-21]. In 2020, Shinozaki-Ushiku et al. [22] identified the first case of gastric carcinoma in which altered immunohistochemical TRK expression and the associated gene fusion transcript could be detected by RNA-seq. However, prior to this, several studies had already demonstrated altered gene expression of TRK in gastric carcinomas [16,38,39]. For example, Lee et al. [40] detected TRK alteration in one of 66 gastric carcinomas by immunohistochemistry and FISH, but no NTRK1 rearrangement was confirmed by NGS. We found seven cases with a immunohistochemical expression of panTRK. However, by analyzing these cases with NGS, no gene fusion transcript could be detected. As is the case for ALK and NUT, NTRK fusions do not seem to be relevant in gastric cancer. On the other hand, panTRK immunohistochemistry has had a relatively low false-positive rate and therefore seems to be an adequate method for screening cases with a specific indication.

Despite the comprehensive analysis of a large cohort, our study has limitations mainly related to its retrospective nature. Our study should be considered an exploratory analysis, and the results should be validated in independent prospective cohorts.

\section{Conclusions}

In summary, our results indicate that neither the expression of ALK, NUT, nor TRK plays a relevant role in gastric cancer. On the other hand, panTRK immunohistochemistry has had a relatively low false-positive rate and therefore seems to be an adequate method for screening cases with a specific indication.

Author Contributions: Conceptualization, B.M., B.G., M.-I.G. and S.D.; formal analysis, M.-I.G. and B.G.; investigation, B.G., M.-I.G., S.D., S.M., D.V. and G.S.; writing-original draft preparation, M.-I.G. and B.G.; writing-review and editing, B.M., B.G., M.-I.G., S.D. and A.A.; visualization, M.-I.G. and B.G.; supervision, B.M. All authors have read and agreed to the published version of the manuscript.

Funding: This study received no external funding. 
Institutional Review Board Statement: This study was approved by the Institutional Review Boards at the Ludwig-Maximilians-University of Munich (reference: 20-0922) and was performed in accordance with the Declaration of Helsinki.

Informed Consent Statement: Patient consent was waived due to the retrospective study design.

Data Availability Statement: The datasets generated during the current work are available from the corresponding author upon reasonable request.

Acknowledgments: The authors are grateful to Jenny Müller, Andrea Seuser, and Christian Beul for excellent technical assistance and to Katja Evert for the supportive scientific exchange.

Conflicts of Interest: The authors have no relevant conflicts of interest to declare.

\section{References}

1. Bray, F.; Ferlay, J.; Soerjomataram, I.; Siegel, R.L.; Torre, L.A.; Jemal, A. Global cancer statistics 2018: GLOBOCAN estimates of incidence and mortality worldwide for 36 cancers in 185 countries. CA Cancer J. Clin. 2018, 68, 394-424; Erratum in CA Cancer J. Clin. 2020, 70, 313. [CrossRef] [PubMed]

2. Zhou, F.; Li, N.; Jiang, W.; Hua, Z.; Xia, L.; Wei, Q.; Wang, L. Prognosis significance of HER-2/neu overexpression/amplification in Chinese patients with curatively resected gastric cancer after the ToGA clinical trial. World J. Surg. Oncol. 2012, 10, 274. [CrossRef] [PubMed]

3. Böger, C.; Behrens, H.-M.; Mathiak, M.; Krüger, S.; Kalthoff, H.; Röcken, C. PD-L1 is an independent prognostic predictor in gastric cancer of Western patients. Oncotarget 2016, 7, 24269-24283. [CrossRef] [PubMed]

4. Muro, K.; Chung, H.C.; Shankaran, V.; Geva, R.; Catenacci, D.; Gupta, S.; Eder, J.P.; Golan, T.; Le, D.T.; Burtness, B.; et al Pembrolizumab for patients with PD-L1-positive advanced gastric cancer (KEYNOTE-012): A multicentre, open-label, phase 1b trial. Lancet Oncol. 2016, 17, 717-726. [CrossRef]

5. Baniak, N.; Senger, J.-L.; Ahmed, S.; Kanthan, S.C.; Kanthan, R. Gastric biomarkers: A global review. World J. Surg. Oncol. 2016, 14, 212. [CrossRef] [PubMed]

6. Ferreira, P.; Oliveira, M.J.; Beraldi, E.; Mateus, A.R.; Nakajima, T.; Gleave, M.; Yokota, J.; Carneiro, F.; Huntsman, D.; Seruca, R.; et al. Loss of functional E-cadherin renders cells more resistant to the apoptotic agent taxol in vitro. Exp. Cell Res. 2005, 310, 99-104. [CrossRef]

7. Cancer Genome Atlas Research Network. Comprehensive molecular characterization of gastric adenocarcinoma. Nature 2014, 513, 202-209. [CrossRef] [PubMed]

8. $\quad$ Cristescu, R.; Lee, J.; Nebozhyn, M.; Kim, K.-M.; Ting, J.C.; Wong, S.S.; Liu, J.; Yue, Y.G.; Wang, J.; Yu, K.; et al. Molecular analysis of gastric cancer identifies subtypes associated with distinct clinical outcomes. Nat. Med. 2015, 21, 449-456. [CrossRef]

9. Hallberg, B.; Palmer, R.H. The role of the ALK receptor in cancer biology. Ann. Oncol. 2016, 27, iii4-iii15. [CrossRef]

10. Ducray, S.P.; Natarajan, K.; Garland, G.D.; Turner, S.D.; Egger, G. The Transcriptional Roles of ALK Fusion Proteins in Tumorigenesis. Cancers 2019, 11, 1074. [CrossRef]

11. Clinical Lung Cancer Genome Project; Network Genomic Medicine. A genomics-based classification of human lung tumors. Sci. Transl. Med. 2013, 5, 209ra153.

12. Schrank, Z.; Chhabra, G.; Lin, L.; Iderzorig, T.; Osude, C.; Khan, N.; Kuckovic, A.; Singh, S.; Miller, R.J.; Puri, N. Current Molecular-Targeted Therapies in NSCLC and Their Mechanism of Resistance. Cancers 2018, 10, 224. [CrossRef] [PubMed]

13. Alese, O.B.; El-Rayes, B.F.; Sica, G.; Zhang, G.; Alexis, D.; La Rosa, F.G.; Varella-Garcia, M.; Chen, Z.; Rossi, M.R.; Adsay, V.; et al. Anaplastic lymphoma kinase (ALK) gene alteration in signet ring cell carcinoma of the gastrointestinal tract. Ther. Adv. Med. Oncol. 2015, 7, 56-62. [CrossRef] [PubMed]

14. Chon, H.J.; Kim, H.R.; Shin, E.; Kim, C.; Heo, S.J.; Lee, C.-K.; Park, J.K.; Noh, S.H.; Chung, H.; Rha, S.Y. The Clinicopathologic Features and Prognostic Impact of ALK Positivity in Patients with Resected Gastric Cancer. Ann. Surg. Oncol. 2015, 22, 3938-3945. [CrossRef]

15. Ying, J.; Lin, C.; Wu, J.; Guo, L.; Qiu, T.; Ling, Y.; Shan, L.; Zhou, H.; Zhao, D.; Wang, J.; et al. Anaplastic Lymphoma Kinase Rearrangement in Digestive Tract Cancer: Implication for Targeted Therapy in Chinese Population. PLoS ONE 2015, 10, e0144731. [CrossRef]

16. Okamura, R.; Boichard, A.; Kato, S.; Sicklick, J.K.; Bazhenova, L.; Kurzrock, R. Analysis of NTRK Alterations in Pan-Cancer Adult and Pediatric Malignancies: Implications for NTRK-Targeted Therapeutics. JCO Precis. Oncol. 2018, 2, 1-20. [CrossRef]

17. Chetty, R. Neurotrophic tropomyosin or t yrosine receptor kinase (NTRK) genes. J. Clin. Pathol. 2019, 72, 187-190. [CrossRef]

18. Cocco, E.; Scaltriti, M.; Drilon, A. NTRK fusion-positive cancers and TRK inhibitor therapy. Nat. Rev. Clin. Oncol. 2018, 15, 731-747. [CrossRef]

19. Doebele, R.C.; Davis, L.E.; Vaishnavi, A.; Le, A.T.; Estrada-Bernal, A.; Keysar, S.B.; Jimeno, A.; Varella-Garcia, M.; Aisner, D.L.; Li, Y.; et al. An Oncogenic NTRK Fusion in a Patient with Soft-Tissue Sarcoma with Response to the Tropomyosin-Related Kinase Inhibitor LOXO-101. Cancer Discov. 2015, 5, 1049-1057. [CrossRef]

20. Amatu, A.; Sartore-Bianchi, A.; Siena, S. NTRK gene fusions as novel targets of cancer therapy across multiple tumour types. ESMO Open 2016, 1, e000023. [CrossRef] 
21. Märkl, B.; Hirschbühl, K.; Dhillon, C. NTRK-Fusions-A new kid on the block. Pathol. Res. Pract. 2019, 215, 152572. [CrossRef]

22. Shinozaki-Ushiku, A.; Ishikawa, S.; Komura, D.; Seto, Y.; Aburatani, H.; Ushiku, T. The first case of gastric carcinoma with NTRK rearrangement: Identification of a novel ATP1B-NTRK1 fusion. Gastric Cancer 2020, 23, 944-947. [CrossRef] [PubMed]

23. French, C.A. NUT Carcinoma: Clinicopathologic features, pathogenesis, and treatment. Pathol. Int. 2018, 68, 583-595. [CrossRef] [PubMed]

24. Dickson, B.C.; Sung, Y.-S.; Rosenblum, M.K.; Reuter, V.E.; Harb, M.; Wunder, J.S.; Swanson, D.; Antonescu, C.R. NUTM1 Gene Fusions Characterize a Subset of Undifferentiated Soft Tissue and Visceral Tumors. Am. J. Surg. Pathol. 2018, 42, 636-645. [CrossRef] [PubMed]

25. Siewert, J.R.; Stein, H.J. Classification of adenocarcinoma of the oesophagogastric junction. Br. J. Surg. 2003, 85, 1457-1459. [CrossRef] [PubMed]

26. Becker, K.; Mueller, J.D.; Schulmacher, C.; Ott, K.; Fink, U.; Busch, R.; Bottcher, K.; Siewert, J.R.; Hofler, H. Histomorphology and grading of regression in gastric carcinoma treated with neoadjuvant chemotherapy. Cancer 2003, 98, 1521-1530. [CrossRef]

27. Songun, I.; Putter, H.; Kranenbarg, E.M.-K.; Sasako, M.; van de Velde, C.J. Surgical treatment of gastric cancer: 15-year follow-up results of the randomised nationwide Dutch D1D2 trial. Lancet Oncol. 2010, 11, 439-449. [CrossRef]

28. Shuster, J.J. Median follow-up in clinical trials. J. Clin. Oncol. 1991, 9, 191-192. [CrossRef]

29. Ahn, S.; Lee, S.-J.; Kim, Y.; Kim, A.; Shin, N.; Choi, K.U.; Lee, C.-H.; Huh, G.Y.; Kim, K.-M.; Setia, N.; et al. High-throughput Protein and mRNA Expression-based Classification of Gastric Cancers Can Identify Clinically Distinct Subtypes, Concordant With Recent Molecular Classifications. Am. J. Surg. Pathol. 2017, 41, 106-115. [CrossRef]

30. Setia, N.; Agoston, A.T.; Han, H.S.; Mullen, J.T.; Duda, D.G.; Clark, J.W.; Deshpande, V.; Mino-Kenudson, M.; Srivastava, A.; Lennerz, J.K.; et al. A protein and mRNA expression-based classification of gastric cancer. Mod. Pathol. 2016, $29,772-784$. [CrossRef]

31. Bronsert, P.; Kohler, I.; Timme, S.; Kiefer, S.; Werner, M.; Schilling, O.; Vashist, Y.; Makowiec, F.; Brabletz, T.; Hopt, U.T.; et al. Prognostic significance of Zinc finger E-box binding homeobox 1 (ZEB1) expression in cancer cells and cancer-associated fibroblasts in pancreatic head cancer. Surgery 2014, 156, 97-108. [CrossRef] [PubMed]

32. Köbel, M.; Piskorz, A.M.; Lee, S.; Lui, S.; LePage, C.; Marass, F.; Rosenfeld, N.; Mes Masson, A.-M.; Brenton, J.D. Optimized p53 immunohistochemistry is an accurate predictor of TP53 mutation in ovarian carcinoma. J. Pathol. Clin. Res. 2016, 2, 247-258. [CrossRef]

33. Grosser, B.; Kohlruss, M.; Slotta-Huspenina, J.; Jesinghaus, M.; Pfarr, N.; Steiger, K.; Novotny, A.; Gaida, M.M.; Schmidt, T.; Hapfelmeier, A.; et al. Impact of Tumor Localization and Molecular Subtypes on the Prognostic and Predictive Significance of p53 Expression in Gastric Cancer. Cancers 2020, 12, 1689. [CrossRef]

34. Ishibashi, Y.; Miyoshi, H.; Hiraoka, K.; Arakawa, F.; Haraguchi, T.; Nakashima, S.; Hashiguchi, T.; Shoda, T.; Hamada, T.; Okawa, T.; et al. Anaplastic lymphoma kinase protein expression, genetic abnormalities, and phosphorylation in soft tissue tumors: Phosphorylation is associated with recurrent metastasis. Oncol. Rep. 2015, 33, 1667-1674. [CrossRef] [PubMed]

35. Huang, H. Anaplastic Lymphoma Kinase (ALK) Receptor Tyrosine Kinase: A Catalytic Receptor with Many Faces. Int. J. Mol. Sci. 2018, 19, 3448. [CrossRef] [PubMed]

36. Van Der Wekken, A.; Pelgrim, R.; Hart, N. 'T.; Werner, N.; Mastik, M.; Hendriks, L.; van der Heijden, E.; Looijen-Salamon, M.; De Langen, A.; Brekel, J.S.-V.D.; et al. Dichotomous ALK-IHC Is a Better Predictor for ALK Inhibition Outcome than Traditional ALK-FISH in Advanced Non-Small Cell Lung Cancer. Clin. Cancer Res. 2017, 23, 4251-4258. [CrossRef]

37. Storck, S.; Kennedy, A.L.; Marcus, K.J.; Teot, L.; Vaughn, J.; Gnekow, A.K.; Märkl, B.; Leuschner, I.; Dubois, S.G.; French, C.A.; et al. Pediatric NUT-midline carcinoma: Therapeutic success employing a sarcoma based multimodal approach. Pediatr. Hematol. Oncol. 2017, 34, 231-237. [CrossRef]

38. Solomon, J.P.; Linkov, I.; Rosado, A.; Mullaney, K.; Rosen, E.Y.; Frosina, D.; Jungbluth, A.A.; Zehir, A.; Benayed, R.; Drilon, A.; et al. NTRK fusion detection across multiple assays and 33,997 cases: Diagnostic implications and pitfalls. Mod. Pathol. 2020, 33, 38-46. [CrossRef]

39. Zehir, A.; Benayed, R.; Shah, R.H.; Syed, A.; Middha, S.; Kim, H.R.; Srinivasan, P.; Gao, J.; Chakravarty, D.; Devlin, S.M.; et al. Mutational landscape of metastatic cancer revealed from prospective clinical sequencing of 10,000 patients. Nat. Med. 2017, 23, 703-713. [CrossRef]

40. Lee, S.J.; Li, G.G.; Kim, S.T.; Hong, M.E.; Jang, J.; Yoon, N.; Ahn, S.M.; Murphy, D.; Christiansen, J.; Wei, G.; et al. NTRK1 rearrangement in colorectal cancer patients: Evidence for actionable target using patient-derived tumor cell line. Oncotarget 2015, 6, 39028-39035. [CrossRef] 